\title{
Persistent detection of Zika virus RNA from an infant with severe microcephaly - a case report
}

\author{
Carlos A. A. Brito ${ }^{1}$, Adélia Henriques-Souza ${ }^{2}$, Cynthia R. P. Soares ${ }^{3}$, Priscila M. S. Castanha ${ }^{3}$, Laís C. Machado ${ }^{4}$, \\ Mylena R. Pereira ${ }^{5}$, Mariana C. M. Sobral ${ }^{4}$, Antonio R. Lucena-Araujo ${ }^{6}$, Gabriel L. Wallau ${ }^{4}$ and Rafael F. O. Franca ${ }^{3 *}$
}

\begin{abstract}
Background: Zika virus (ZIKV) is a recently emerged arbovirus, which infection during pregnancy is associated with a series of congenital malformations, collectively denominated Congenital Zika Syndrome (CZS). Following infection, ZIKV RNA has a median duration period of 10 days in plasma and up to 6 months in semen in immunocompetent adult individuals. Moreover, ZIKV is able to replicate and persist in fetal brains and placentas, consequently, infection is associated with pregnancy loss, albeit the pathogenic mechanisms are still unknown.
\end{abstract}

Case presentation: Here we report a CZS case of an infant born during the ZIKV outbreak in northeast Brazil, the child presented recurrent episodes of seizures with prolonged presence of ZIKV RNA on the central nervous system (CNS) and blood. ZIKV RNA was identified and partially sequenced from a sample of cerebrospinal fluid (CSF) obtained from the infant with 6 months of life, and later from another sample after the infant completed 17 months of life. Commonly congenital infections were discarded based on STORCH (syphilis, toxoplasmosis, rubella, cytomegalovirus and herpes simplex virus) negative laboratory results. Presence of specific ZIKV antibodies on both mother and children confirmed the association of severe microcephaly and ZIKV infection, diagnosed after birth.

Conclusions: Altogether, our data raise the possibility that CZS cases may result in prolonged viral presence, these findings could be useful for therapy and diagnostic recommendations.

Keywords: Zika virus, Neurological disease, Microcephaly, Virus persistence

\section{Background}

Zika virus (ZIKV) was firstly isolated from rhesus macaques in the Zika forest of Uganda in 1947 [1]. The virus is mainly transmitted by infected Aedes mosquitoes, however other modes of infection have been reported, such as sexual and perinatal transmission [2]. Infections are usually not detected (asymptomatic), although $20 \%$ of the infected individuals progress to a clinically apparent febrile illness with commonly reported symptoms including mild fever, rash, arthralgia, headache, and conjunctivitis [3]. Additionally, severe neurologic manifestations such as Guillain-Barre Syndrome (GBS) in adults and the newly described

\footnotetext{
* Correspondence: rafael.franca@cpqam.fiocruz.br

${ }^{3}$ Department of Virology and Experimental Therapy, Aggeu Magalhães Institute, Oswaldo Cruz Foundation - FIOCRUZ, Avenida Professor Moraes Rego s/n, Recife, PE 50740-465, Brazil

Full list of author information is available at the end of the article
}

Congenital Zika Syndrome (CZS), a wide spectrum of congenital malformations in fetuses and newborns, have been described [4]. ZIKV attracted a lot of attention after a large outbreak in Brazil in 2015, which was associated with an increased number of microcephaly cases (a congenital malformation where the head circumference is smaller than 2 standard deviations below the mean for the same age and sex) [5].

ZIKV immunopathogenesis is not completely understood. As reported for other viruses of the same family, ZIKV infection is usually self-limited, resulting in viral clearance in approximately 1 week after infection, although prolonged viremia has been documented, especially in pregnant women and in the semen of infected men [6-9]. ZIKV is highly neurotropic and replicates in the central nervous system (CNS). In fact, in situ hybridization screening demonstrated the presence of 
ZIKV RNA in brains of fetuses from pregnancy losses [10] and different experimental approaches identified ZIKV in the CNS of infected animals at different times post-infection $[11,12]$. Interestingly, a recent study demonstrated that in blood, ZIKV is rapidly controlled, however, the virus is able to persist for long periods in the CNS (up to 42 days in cerebrospinal fluid (CSF) of experimentally infected Rhesus monkeys) [13].

ZIKV infection can be diagnosed through viral RNA detection by the use of Real-Time Reverse-TranscriptasePolymerase-Chain-Reaction (rRT-PCR) assays. The presence of anti-ZIKV IgM antibodies is also an indication of recent infection, although the complete kinetics of IgM production have not yet fully described [14]. Moreover, the presence of anti-Zika IgM antibodies in the CSF of microcephaly-diagnosed neonates is a confirmatory test in cases where Zika infection during pregnancy is suspected [15]. Experimentally, ZIKV is able to infect human neural progenitor cells (NPC), impairing their development [16]. In mice, ZIKV infection results in cell-cycle arrest, apoptosis, and inhibition of NPC differentiation, which results in cortical thinning and microcephaly $[17,18]$. Altogether, these findings confirm that ZIKV is able to directly infect the CNS and several independent publications have demonstrated the role of ZIKV in microcephaly development [19]. However, the clinical evolution of the infants diagnosed with microcephaly, due to the direct infection of the CNS during pregnancy, has not yet been assessed.

\section{Case presentation}

In September 2015, a middle age woman (44 years old) resident from Recife, northeast Brazil, gave birth to a male in a local public hospital. At birth, the neonate had $2580 \mathrm{~g}, 45.5 \mathrm{~cm}$ in length and head circumference of $29.5 \mathrm{~cm}$ (suspected case of microcephaly). The child was born after a 38 weeks single-gestation period (full-term), during the first trimester of pregnancy the mother reported a febrile episode followed by headache, joint pain, and rash, the symptoms described did not last more than 3 days and no other symptoms were reported, dengue virus (DENV) IgM serology was negative. At 20 weeks of the gestational age, a prenatal intrauterine ultrasound was performed and the diagnosis was consistent with congenital microcephaly. After birth, during the first month of life, a complete brain imaging examination of the infant evidenced the findings consistent with severe microcephaly, following the protocol of the Brazilian Ministry of Health for Microcephaly Investigation. Brain imaging (magnetic resonance) demonstrated the presence of lissencephaly, decreased brain parenchymal volume, decreased cortical mantle and white matter together with hypoplasia of the corpus callosum. Computed tomography and transfontanellar cranial ultrasound evidenced the presence of multiple brain calcifications, colpocephaly and gliosis in the left cerebellar hemisphere were also documented (Fig. 1a-i). Serological tests were performed on the mother (18 days after she gave birth), the results for STORCH laboratory screen (syphilis, toxoplasmosis, rubella, cytomegalovirus and herpes simplex virus), Parvovirus B19 IgM and chikungunya virus (CHIKV) IgM were all negative (Fig. 2), no ZIKV serological (ELISA or $\mathrm{PRNT}_{50}$ ) or molecular tests (rRT-PCR) were performed during pregnancy since these tests were not available at that time, being implemented in Brazil only later in 2016.

Laboratory STORCH tests were also performed in the child with 1 month of life, the results were all negative, including chikungunya IgM and anti-Epstein-Barr virus (EBV) IgM (Fig. 2). No Zika virus serology or molecular tests were performed on the child and no samples were stored for later investigations. After 1 month of life, a detailed neurological examination in the infant evidenced upper and lower limb spasticity (mainly on upper limbs), extreme irritability, continuous cry and head circumference measurement of $31 \mathrm{~cm}$ was consistent with severe microcephaly $(<3 \mathrm{SD}$ on the Fenton growth chart).

With approximately 6 months of life, the child was admitted to a local hospital after presenting several recurrent seizure episodes. Electroencephalographic (EEG) examination evidenced the presence of focal frontal epileptiform discharges. At the hospital, a blood and a cerebrospinal fluid (CSF) samples were collected. Laboratory results of serum and CSF confirmed the presence of ZIKV viral RNA on both samples, analyzed by rRT-PCR following a well-established laboratory protocol [20]. Additionally, rRT-PCR for chikungunya (CHIKV) and ELISA tests were all negative in serum and CSF as follows anti-ZIKV IgM, anti-DENV I, M and IgG, anti-CHIKV IgM and IgG (Fig. 2). To confirm ZIKV infection a plaque reduction neutralization test $\left(\mathrm{PRNT}_{50}\right)$ was performed from the CSF sample, a ZIKV positive neutralization titer of 99 confirmed the previous infection, no neutralizing DENV antibody titers were observed (Table 1 and Fig. 2).

The interesting presence of ZIKV RNA previously identified at 6 months of life prompted us to investigate ZIKV persistence in a second sample collected with the age of 1 year and 5 months (here denominated 17 months for a better understanding). Given the risk of an invasive lumbar puncture, only a blood sample was collected from the child following a regular visit to the pediatrician, on the same occasion, a blood sample from the mother was also requested. On child serum, after 17 months of life, ZIKV rRT-PCR was still positive. Serology was negative for the tested arboviruses as follows anti-ZIKV IgM, anti-DENV IgM and IgG, anti-CHIKV IgM and IgG (Fig. 2). A plaque reduction neutralization test $\left(\mathrm{PRNT}_{50}\right)$ was 



Fig. 1 Brain Imaging after birth. a MRI Sagittal T1 weighted image: hypogenesis of the corpus callosum, enlarged cisterna magna, and ventriculomegaly. b MRI Axial T2 weighted image: simplified frontal gyral pattern, ventriculomegaly. c Axial T1 weighted image: pachygyria/lissencephaly in the frontal lobe, ventriculomegaly. d, e, f MRI Axial T1 weighted image: simplified frontal gyral pattern, ventriculomegaly, cerebellum hemisphere hypoplasia. $\mathbf{g}, \mathbf{h}, \mathbf{i}$ Axial non-contrast CT image: multiple bilateral calcifications in the junction between cortical and subcortical white matter, ventricular enlargement

again performed on child serum, ZIKV positive neutralization dilution titer of 527.9 reinforced our previous result of ZIKV infection, and again no neutralizing DENV antibody titers were observed. Moreover, the presence of a high titer of ZIKV neutralization antibodies (titer of 972) on mother's serum confirms Zika virus infection (Table 1 and Fig. 2). On mother's serum the presence of positive DENV neutralization titer is not surprisingly since dengue virus is endemic in Brazil, especially in the northeast region. 


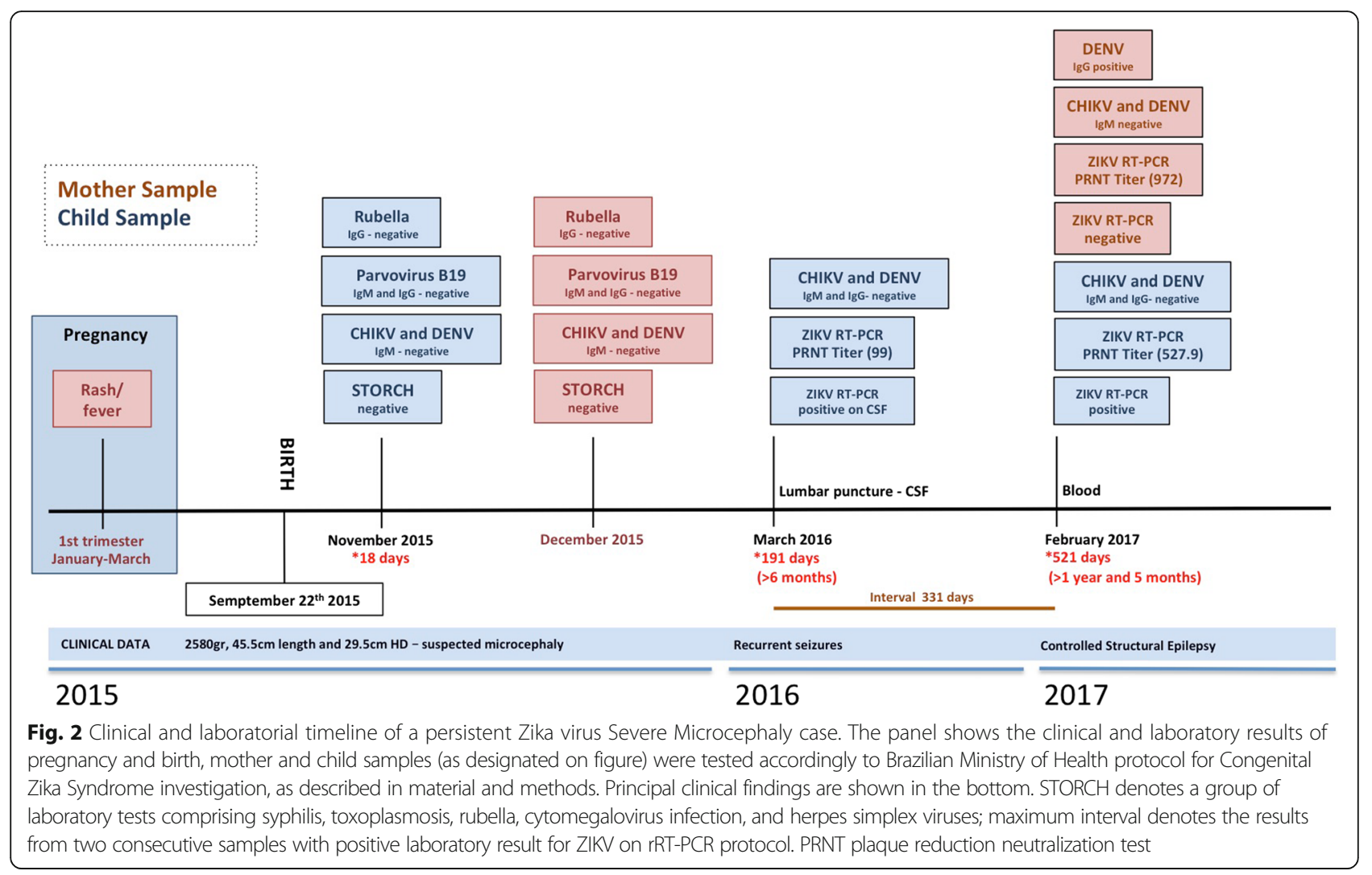

It's intriguing the presence of ZIKV RNA for such a long time and since samples were stored with RNA preservative solution viral isolation was not attempted. Thus, to further confirm the presence of ZIKV on child CSF and serum we performed genome sequencing direct from blood and CSF positive samples, employing a previously published protocol [21]. We obtained two partial ZIKV genomes from samples CSF-six-months and serum-17-months of 6653 and 5292 base pairs, respectively, corresponding to 60.6 and $48.9 \%$ of genomic coverage (Fig. 3). Phylogenetic analysis showed that these two draft genomes belong to the Asian genotype and clustered closely with a ZIKV isolate from Paraíba/ Brazil (Fig. 4), located around $120 \mathrm{~km}$ from where the mother gave birth. Since six-months-CSF sample differs from Paraiba_01 ZIKV strain by two single nucleotide polymorphisms (SNPs) in the envelope gene (E) and serum-17-months sample differs from Paraíba_01 by three SNPs, these results are consistent with a single ZIKV infecting strain. The child is being followed in a local hospital. Clinical evolution consists mainly in delayed neuropsychomotor development, dysphagia (difficulty swallowing), visual impairment, and double spastic hemiplegia. Treatment consists of clobazam (antiepileptic drug). After almost 2 years of life, the child presents controlled structural epilepsy.

\section{Sample collection and processing}

CSF and blood were collected through standard procedures. Anti-dengue and anti-chikungunya virus IgM and IgG antibodies were detected by commercially available capture ELISA kits (Anti-Dengue Virus ELISA IgM/IgG

Table 1 Plaque Reduction Neutralization Test (PRNT) for Zika virus (ZIKV) and dengue virus (DENV1-4) in maternal serum, child serum and cerebrospinal fluid (CSF) specimens collected at different ages of the neonate with Congenital Zika Syndrome

\begin{tabular}{|c|c|c|c|c|c|c|}
\hline \multirow[t]{2}{*}{ Sample } & \multirow{2}{*}{$\begin{array}{l}\text { Age at } \\
\text { testing }\end{array}$} & \multicolumn{5}{|c|}{$\mathrm{PRNT}_{50}$ Titer } \\
\hline & & ZIKV & DENV-1 & DENV-2 & DENV-3 & DENV-4 \\
\hline Mother (serum) & 17 months $^{a}$ & 972 & $<20$ & $<20$ & 689.5 & 262.7 \\
\hline \multicolumn{7}{|l|}{ Neonate } \\
\hline Serum & 17 months & 527.9 & $<20$ & $<20$ & $<20$ & $<20$ \\
\hline CSF & 6 months & 99 & $<20$ & $<20$ & $<20$ & $<20$ \\
\hline
\end{tabular}

${ }^{\mathrm{a}}$ Age of the child at the time of sample collection 


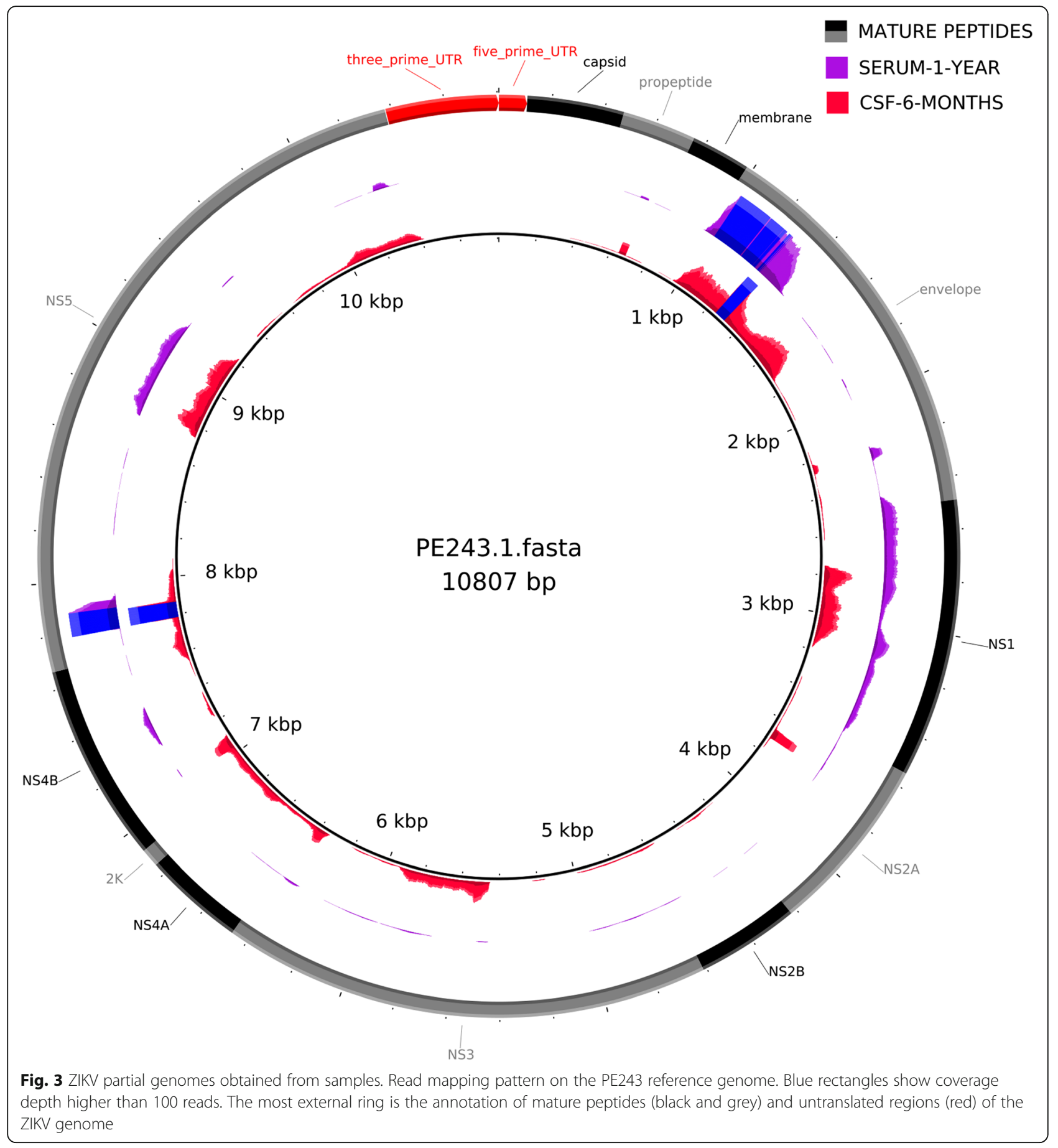

and Anti-CHIKV IgM/IgG from EuroImmun AG, Luebeck - Germany), following manufacturers instructions. Serotype-specific anti-DENV and anti-Zika antibodies were assessed by plaque reduction neutralization test (PRNT). The antibody titer was determined as the serum dilution that inhibited $50 \%$ of the tested virus inoculum $\left(\mathrm{PRNT}_{50}\right)$. Anti-Zika IgM antibodies were detected by Capture Enzyme-Linked Immunosorbent Assay (MAC-ELISA). Viral RNA was extracted by the use of a QIAamp Viral RNA kit (Qiagen, Hilden Germany), following manufacturers instructions and rRT-qPCR reactions were performed from purified RNA serum samples accordingly to Lanciotti et al.[20], with modifications. Briefly, reactions were performed with the kit GoTaq ${ }^{\circ}$ Probe 1-Step RT-qPCR System (Promega, Fitchburg, USA) in a $20 \mu \mathrm{l}$ final volume, primers and probes employed were as follows: Zika 1087 5'-CCGC TGCCCAACACAAG-3', Zika1163c 5'-CCACTAACG 


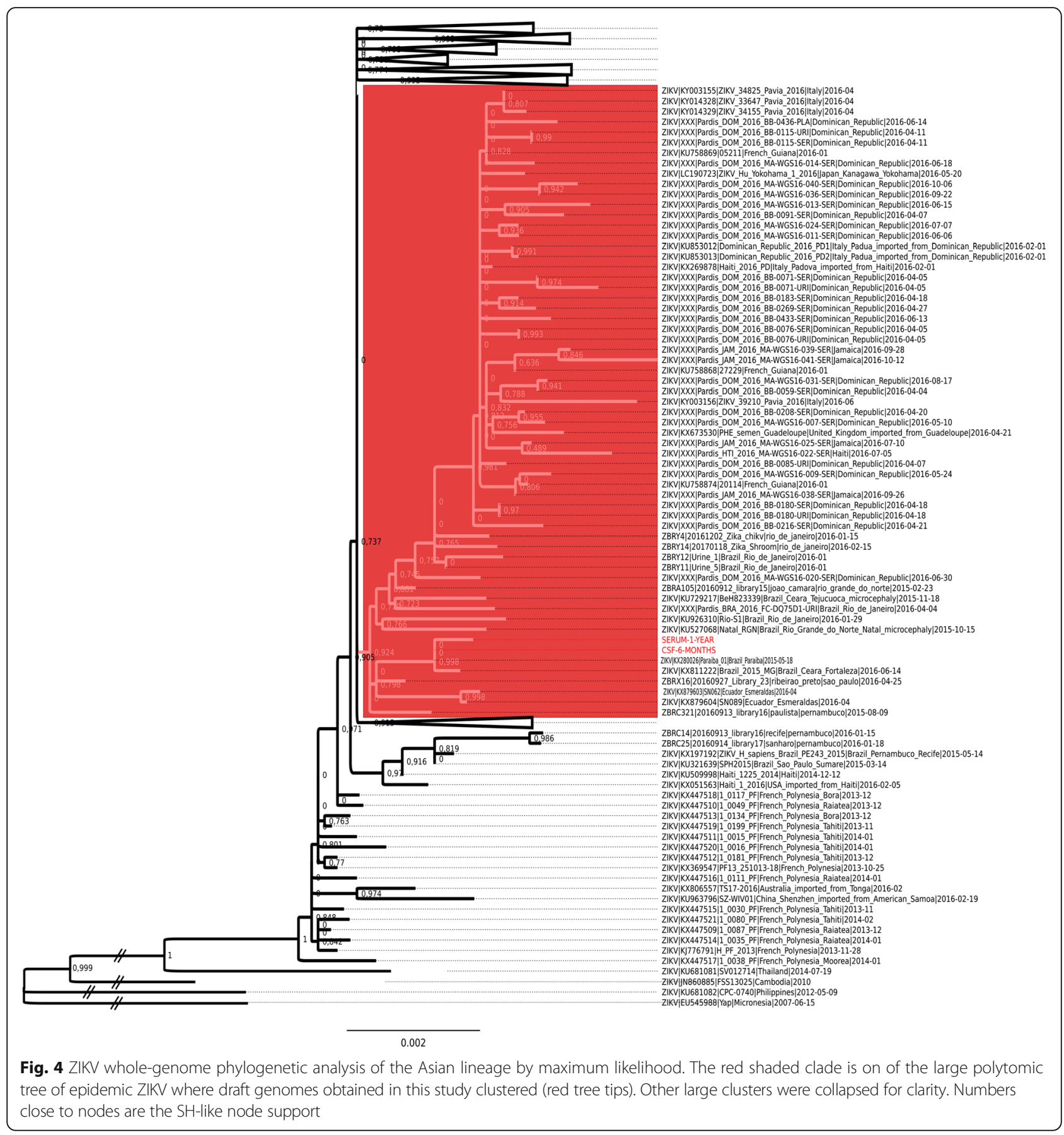

TTCTTTTGCAGACAT-3' and Zika 1087 VIC (probe) 5'AGCCTACCTTGACAAGCAGTCAGACACTCAA-3'. Samples with a $\mathrm{Ct}$ value $<38$ in duplicate wells were considered to be positive for ZIKV. For sequencing, total RNA extracted as above was converted to cDNA and amplified, PCR products were then quantified and libraries were prepared with Nextera XT Library Prep Kit (Illumina, San Diego - USA), MiSeq Reagent Kit V3 of 150 cycles was used to sequence employing a paired-end strategy. Mapped reads were visualized and majority rule consensus genomes were extracted with Integrated Genome Viewer (IGV) and carefully checked on the mapping results. Phylogenetic reconstruction was performed on an alignment of the coding region of all ZIKV genomes available by maximum likelihood. All sequences were aligned with Mafft v 7.

\section{Discussion}

Here, we reported a case of an infant diagnosed with severe microcephaly presenting virus persistence for 
several months after birth. The child was born in 2015, during the ZIKV outbreak in Brazil, the symptoms reported by the mother during pregnancy are consistent with ZIKV infection, albeit laboratory confirmation has not been performed since ZIKV specific detection protocols were only implemented later in Brazil. On the other hand, after giving birth, a complete laboratory screening for the most common congenital infections was performed and the results were all negative. At birth, the neonate was not tested for ZIKV infection, however, the presence of ZIKV-neutralizing antibodies on a CSF sample collected 6 months after birth confirms the previous infection. Based on that, a strong argument between the clinical signs of severe microcephaly and ZIKV infection can be implied. In fact, detection of anti-ZIKV IgM antibodies in the CSF is strongly associated with ZIKV congenital infection [15]. Moreover, following infection, ZIKV IgM antibodies increases from 4 to 7 days, persisting for several weeks. On the other hand, neutralizing antibodies are long-lasting. Here the presence of ZIKV neutralizing antibodies is a confirmation of ZIKV exposure, albeit the participation of maternally transferred antibodies should be also considered. During the clinical interview we did not include data about breastfeeding, and since dysphagia, including breastfeeding difficulties, has been documented in several children with CZS [22], we could not correctly evaluate the role of maternally transferred antibodies in the child immune response.

After recurrent seizure episodes followed by the need for hospitalization, the neurologist performed a CSF sampling from the child with the age of 6 months and laboratory RT-PCR analysis identified the presence of ZIKV on CSF. Since birth, the child has been followed by a team of pediatricians for treatment and early stimulation, thus after 17 months of life, the child had another sample collected which was tested positive for ZIKV presence. The maximum interval between consecutive ZIKV rRT-PCR positive samples from this case was of 331 days, to our knowledge, this is the longest report of ZIKV persistence in a single individual. Virus persistence for such a long time has several implications: i) infected individuals could act as reservoirs contributing to maintenance of virus circulation; ii) continuous immune stimulation, by the presence of ZIKV in different body tissues, can result in recurrent organ damage with consequent disease worsening; iii) virus persistence on CZS cases may require differential treatment (e.g., use of antivirals associated with anti-inflammatory drugs). By comparing the levels of ZIKV-neutralizing antibodies from early samples, we could have captured a better picture of the child's immunity, unfortunately, we were not able to access these samples (first month of life). These findings presented here are certainly not common to all CZS cases and could be partially explained by i) re-infection - the infant was born during a highly ZIKV circulation period and since protection of neonates are mostly acquired by maternal antibodies transference on breast milk and especially by the fact the adaptive immune response on early life is still on development (characterized by higher induction of Th2-cell polarizing cytokines and suboptimal Th1 responses and B-cell differentiation), neonates are more susceptible to different pathogens [23], thus, the child may have been re-infected after birth; ii) infection during fetal development may lead to tolerization - in this scenario $\mathrm{T}$ and $\mathrm{B}$ cell responses are not effective, consequently contributing to enhanced infection susceptibility.

The ZIKV microcephaly outbreak was first documented in Brazil in 2015, and although neuro-developmental malformations have been linked to many other different viral infections, ZIKV pathogenesis is still not fully understood. However, it is well accepted that infection during the first trimester of pregnancy may result in congenital malformations [21]. Zika viral RNA was found on saliva [24], amniotic fluid [25], urine [26], cerebrospinal fluid (CSF), blood, semen and tears $[27,28]$. Interestingly, ZIKV can persist on different body compartments for longer periods. In fact, experimentally infected rhesus macaques presented ZIKV viral RNA for several weeks post infection in neuronal, lymphoid, joint/muscle and male/female reproductive tissues [13]. Additionally, in cases of human infection, the virus can persist for more than 6 months on semen [7].

\section{Conclusion}

Here, we added more data about ZIKV persistence, even if it is based on a single case. Clearly, we cannot rule out the possibility of two independent Zika infections between the different time points analyzed, albeit both samples were sequenced and results are consistent with a single infecting strain. Our results here presented shows compelling evidence of chronification of infection, which has not yet been investigated in CZS cases. Based on that, we propose new studies to better understand the clinical evolution of the CZS documented cases.

\section{Abbreviations \\ CDNA: Complementary deoxyribonucleic acid; CHIKV: Chikungunya virus; CNS: Central nervous system; CSF: Cerebrospinal fluid; CZS: Congenital Zika Syndrome; DENV: Dengue virus; EBV: Epstein-Barr virus; EEG: Electroencephalography; ELISA: Enzyme-Linked Immunosorbent Assay; GBS: Guillain-Barre Syndrome; IgG: Immunoglobulin G; IgM: Immunoglobulin M; NPC: Neuroprogenitor cells; NS5: Nonstructural protein 5; PCR: Polymerase chain reaction; PRNT $_{50}$ : Plaque Reduction Neutralization Test 50\%; RNA: Ribonucleic acid; rRT-PCR: Real Time Reverse-Transcriptase-Polymerase-Chain-Reaction; SNPs: Single nucleotide polymorphisms; STORCH: A list of laboratory tests encompassing Syphilis, Toxoplasma gondii, Rubella, Cytomegalovirus and Herpes Simplex virus; ZIKV: Zika virus}

\section{Acknowledgments}

The authors thank the Fiocruz Sequencing Platform (Subunidade NGS - Rede de Plataformas PDTIS, FIOCRUZ/PE) for the use of its Next Generation Sequencing facilities. 


\section{Funding}

The research leading to these results received funding from the FACEPE Fundação de Amparo à Ciência e Tecnologia de Pernambuco, grant agreement nos. APQ-0055.2.11/16 and APQ- 0044.2.11/16 and CNPq - Conselho Nacional de Desenvolvimento Científico e Tecnológico, grant agreement 439975/2016-6, Coordenação de Aperfeiçoamento de Pessoal de Nível Superior - CAPES 88887.116624/2016-01 under RFOF coordination and responsibility and APQ-0078-2.02/16 under GLW coordination. The funders had no role in study design, data collection and analysis, decision to publish, or preparation of the manuscript.

\section{Availability of data and materials}

All the information and methods applied supporting our conclusions and relevant references are included in the manuscript. The data that support the findings of this study are available from the corresponding author upon reasonable request.

\section{Authors' contributions}

CAAB and AHS contributed to the management of this patient CRPS, PMSC, LCM, MRP, and MCMS contributed to sample processing and laboratory data, ARLA, GLW and RFOF contributed to data analysis, study funding and manuscript preparation. All authors read and approved the final manuscript.

\section{Ethics approval and consent to participate}

Study methods were ethically reviewed and approved by Oswaldo Cruz Foundation - Fiocruz Ethics Review Board CAAE \#511.06115.8 0005190. The aims of our study were explained, and written informed consent was obtained.

\section{Consent for publication}

Written informed consent was obtained from the patient for publication of this Case Report and any accompanying images. A copy of the written consent is available for review by the Editor-in-Chief of this journal.

\section{Competing interests}

The authors declare that they have no competing interests.

\section{Publisher's Note}

Springer Nature remains neutral with regard to jurisdictional claims in published maps and institutional affiliations.

\section{Author details}

${ }^{1}$ Department of Clinical Medicine, Federal University of Pernambuco - UFPE, Recife 50670-901, Brazil. Department of Pediatrics, Hospital da Restauração, Recife 50110-900, Brazil. ंDepartment of Virology and Experimental Therapy, Aggeu Magalhães Institute, Oswaldo Cruz Foundation - FIOCRUZ, Avenida Professor Moraes Rego s/n, Recife, PE 50740-465, Brazil. ${ }^{4}$ Department of Entomology, Oswaldo Cruz Foundation - FIOCRUZ, Aggeu Magalhães Institute, Recife 50740-465, Brazil. ${ }^{5}$ Department Veterinary Medicine, Federal Rural University of Pernambuco - UFRPE, Recife 52171-900, Brazil. ${ }^{6}$ Department of Biophysics, Federal University of Pernambuco - UFPE, Recife 50670-901, Brazil.

Received: 22 March 2018 Accepted: 3 August 2018 Published online: 10 August 2018

\section{References}

1. Dick GWA, Kitchen SF, Haddow AJ. Zika virus. I. Isolations and serological specificity. Trans R Soc Trop Med Hyg. 1952:46:509-20. Available from: http://www.ncbi.nlm.nih.gov/pubmed/12995440. Cited 1 Sept 1952.

2. Gregory CJ, Oduyebo T, Brault AC, Brooks JT, Chung K-W, Hills S, et al. Modes of Transmission of Zika Virus. J Infect Dis. 2017;216:S875-83. Available from: http://www.ncbi.nlm.nih.gov/pubmed/29267909. Cited 16 Dec 2017.

3. Lazear HM, Diamond MS. Zika Virus: New Clinical Syndromes and Its Emergence in the Western Hemisphere. J Virol. 2016;90:4864-75. Available from: http://www.ncbi.nlm.nih.gov/pubmed/26962217. Cited 15 May 2016.

4. Petersen LR, Jamieson DJ, Powers AM, Honein MA. Zika Virus. N Engl J Med. 2016;374:1552-63. Available from: http://www.ncbi.nlm.nih.gov/pubmed/ 27028561. Cited 21 Apr 2016.

5. Bogoch II, Brady OJ, Kraemer MUG, German M, Creatore MI, Kulkarni MA, et al. Anticipating the international spread of Zika virus from Brazil. Lancet
(London, England). 2016;387:335-6. Available from: http://www.ncbi.nlm.nih. gov/pubmed/26777915. Cited 23 Jan 2016.

6. Atkinson B, Hearn P, Afrough B, Lumley S, Carter D, Aarons EJ, et al. Detection of Zika Virus in Semen. Emerg Infect Dis. 2016;22:940. Available from: http://www.ncbi.nlm.nih.gov/pubmed/27088817. Cited 1 May 2016.

7. Gaskell KM, Houlihan C, Nastouli E, Checkley AM. Persistent Zika Virus Detection in Semen in a Traveler Returning to the United Kingdom from Brazil, 2016. Emerg Infect Dis. 2017;23 Available from: http://wwwnc.cdc. gov/eid/article/23/1/16-1300_article.htm. Cited 1 Jan 2017.

8. Lozier MJ, Rosenberg ES, Doyle K, Adams L, Klein L, Muñoz-Jordan J, et al. Prolonged detection of Zika virus nucleic acid among symptomatic pregnant women: a cohort study. Clin Infect Dis. 2018; Available from: http://www.ncbi.nlm.nih.gov/pubmed/29534160. Cited 9 Mar 2018.

9. Meaney-Delman D, Oduyebo T, Polen KND, White JL, Bingham AM, Slavinski SA, et al. Prolonged Detection of Zika Virus RNA in Pregnant Women. Obstet Gynecol. 2016;128:724-30. Available from: http://www.ncbi.nlm.nih. gov/pubmed/27479770. Cited 1 Oct 2016.

10. Bhatnagar J, Rabeneck DB, Martines RB, Reagan-Steiner S, Ermias Y, Estetter LBC, et al. Zika Virus RNA Replication and Persistence in Brain and Placental Tissue. Emerg Infect Dis. 2017;23:405-14. Available from: http://www.ncbi. nlm.nih.gov/pubmed/27959260. Cited 15 Mar 2017.

11. Li H, Saucedo-Cuevas L, Regla-Nava JA, Chai G, Sheets N, Tang W, et al. Zika Virus Infects Neural Progenitors in the Adult Mouse Brain and Alters Proliferation. Cell Stem Cell. 2016;19:593-8. Available from: http://www.ncbi. nlm.nih.gov/pubmed/27545505. Cited 3 Nov 2016.

12. Manangeeswaran $M$, Ireland DDC, Verthelyi D. Zika (PRVABC59) Infection Is Associated with T cell Infiltration and Neurodegeneration in CNS of Immunocompetent Neonatal C57BI/6 Mice. PLoS Pathog. 2016;12:e1006004. Available from: http://www.ncbi.nlm.nih.gov/pubmed/27855206. Cited 17 Nov 2016.

13. Aid M, Abbink P, Larocca RA, Boyd M, Nityanandam R, Nanayakkara $O$, et al. Zika Virus Persistence in the Central Nervous System and Lymph Nodes of Rhesus Monkeys. Cell. 2017;169:610-620.e14. Available from: http://www. ncbi.nlm.nih.gov/pubmed/28457610. Cited 4 May 2017.

14. Singh RK, Dhama K, Karthik K, Tiwari R, Khandia R, Munjal A, et al. Advances in Diagnosis, Surveillance, and Monitoring of Zika Virus: An Update. Front Microbiol. 2017:8:2677. Available from: http://www.ncbi.n/m.nih.gov/ pubmed/29403448. Cited 19 Jan 2017.

15. Cordeiro MT, Pena LJ, Brito CA, Gil LH, Marques ET. Positive IgM for Zika virus in the cerebrospinal fluid of 30 neonates with microcephaly in Brazil. Lancet (London, England). 2016;387:1811-2. Available from: http://www. ncbi.nlm.nih.gov/pubmed/27103126. Cited 30 Apr 2016.

16. Tang H, Hammack C, Ogden SC, Wen Z, Qian X, Li Y, et al. Zika Virus Infects Human Cortical Neural Progenitors and Attenuates Their Growth. Cell Stem Cell. 2016;18:587-90. Available from: http://www.ncbi.nlm.nih.gov/pubmed/ 26952870. Cited 5 May 2016.

17. Cugola FR, Fernandes IR, Russo FB, Freitas BC, Dias JLM, Guimarães KP, et al. The Brazilian Zika virus strain causes birth defects in experimental models. Nature. 2016;534:267-71. Available from: http://www.ncbi.nlm.nih.gov/ pubmed/27279226. Cited 9 June 2016.

18. Li C, Xu D, Ye Q, Hong S, Jiang Y, Liu X, et al. Zika Virus Disrupts Neural Progenitor Development and Leads to Microcephaly in Mice. Cell Stem Cell. 2016;19:120-6. Available from: http://www.ncbi.nlm.nih.gov/pubmed/ 27179424. Cited 7 July 2016

19. de Araújo TVB, de Ximenes RAA, de Miranda-Filho DB, Souza WV, Montarroyos UR, de Melo APL, et al. Association between microcephaly, Zika virus infection, and other risk factors in Brazil: final report of a case-control study. Lancet Infect Dis. 2018;18:328-36. Available from: http://www.ncbi.nlm.nih.gov/pubmed/ 29242091. Cited 11 Mar 2018.

20. Lanciotti RS, Kosoy OL, Laven JJ, Velez JO, Lambert AJ, Johnson AJ, et al. Genetic and serologic properties of Zika virus associated with an epidemic, Yap State, Micronesia, 2007. Emerg Infect Dis. 2008;14:1232-9. Available from: http://www.ncbi.nlm.nih.gov/pubmed/18680646. Cited 1 Aug 2008.

21. Soares de Souza A, Moraes Dias C, Braga FDCB, Terzian ACB, Estofolete CF, Oliani AH, et al. Fetal Infection by Zika Virus in the Third Trimester: Report of 2 Cases. Clin Infect Dis. 2016;63:1622-5. Available from: http://www.ncbi. nlm.nih.gov/pubmed/27601223. Cited 15 Dec 2016.

22. Leal MC, van der Linden V, Bezerra TP, de Valois L, Borges ACG, Antunes MMC, et al. Characteristics of Dysphagia in Infants with Microcephaly Caused by Congenital Zika Virus Infection, Brazil, 2015. Emerg Infect Dis. 2017;23:1253-9. Available from: http://www.ncbi.nlm.nih.gov/pubmed/ 28604336. Cited 15 Aug 2017. 
23. Zhang X, Zhivaki D, Lo-Man R. Unique aspects of the perinatal immune system. Nat Rev Immunol. 2017;17:495-507. Available from: http://www. ncbi.nlm.nih.gov/pubmed/28627520. Cited 19 Aug 2017.

24. Musso D, Roche C, Nhan T-X, Robin E, Teissier A, Cao-Lormeau V-M. Detection of Zika virus in saliva. J Clin Virol. 2015;68:53-5. Available from: http://www.ncbi.nlm.nih.gov/pubmed/26071336. Cited 29 July 2015.

25. Calvet G, Aguiar RS, Melo ASO, Sampaio SA, de Filippis I, Fabri A, et al. Detection and sequencing of Zika virus from amniotic fluid of fetuses with microcephaly in Brazil: a case study. Lancet Infect Dis. 2016;16:653-60. Available from: http://www.ncbi.nlm.nih.gov/pubmed/26897108. Cited 18 June 2016

26. Gourinat A-C, O'Connor O, Calvez E, Goarant C, Dupont-Rouzeyrol M. Detection of Zika virus in urine. Emerg Infect Dis. 2015;21:84-6. Available from: http://www.ncbi.n/m.nih.gov/pubmed/25530324. Cited 1 Jan 2015.

27. Paz-Bailey G, Rosenberg ES, Doyle K, Munoz-Jordan J, Santiago GA, Klein L, et al. Persistence of Zika Virus in Body Fluids - Preliminary Report. N Engl J Med. 2017; Available from: http://www.ncbi.nlm.nih.gov/pubmed/28195756. Cited 14 Feb 2017.

28. Swaminathan S, Schlaberg R, Lewis J, Hanson KE, Couturier MR. Fatal Zika Virus Infection with Secondary Nonsexual Transmission. N Engl J Med. 2016; 375:1907-9. Available from: http://www.ncbi.nlm.nih.gov/pubmed/ 27681699. Cited 10 Nov 2016

Ready to submit your research? Choose BMC and benefit from:

- fast, convenient online submission

- thorough peer review by experienced researchers in your field

- rapid publication on acceptance

- support for research data, including large and complex data types

- gold Open Access which fosters wider collaboration and increased citations

- maximum visibility for your research: over $100 \mathrm{M}$ website views per year

At $\mathrm{BMC}$, research is always in progress.

Learn more biomedcentral.com/submissions 